\title{
The ionic mechanism of the Purkinje cell dendritic spikes generation and propagation: a model exploration
}

\author{
Yunliang Zang ${ }^{*}$, Erik De Schutter \\ From 24th Annual Computational Neuroscience Meeting: CNS*2015 \\ Prague, Czech Republic. 18-23 July 2015
}

Due to the lack of sodium channel expression in the Purkinje cell (PC) dendrite, the passively propagated sodium spikes can hardly be detected in the dendrite. However, the substantial expression of $\mathrm{T}$ type calcium channels $\left(\mathrm{I}_{\mathrm{CaT}}\right)$ and $\mathrm{P}$ type calcium channels $\left(\mathrm{I}_{\mathrm{CaP}}\right)$ can cause local regenerative spikes to occur in the dendrite after receiving a parallel fiber (PF) stimulus [1].

In this study, with the previously published PC dendrite model [2] from our group as the starting point, we have built a new PC dendrite model incorporating the low threshold A-type $\mathrm{K}^{+}$current $\left(\mathrm{I}_{\mathrm{KA}}\right)$ [3], high threshold activated $\mathrm{K}^{+}$current $\left(\mathrm{I}_{\mathrm{KV} 3}\right)$ and hyperpolarizationactivated cation current $\left(\mathrm{I}_{\mathrm{h}}\right)$. In our model, in agreement with experimental observations [1], the EPSP amplitude increases nonlinearly with the strength of the PF synaptic input until it reaches the spike threshold. During this range, we find that $\mathrm{I}_{\mathrm{CaT}}$ amplifies the EPSP caused by PF synaptic input to boost the EPSP close to the spike threshold. Around the spike threshold there is an obvious spike delay due to the interactive role of $\mathrm{I}_{\mathrm{KA}}$ and $\mathrm{I}_{\mathrm{CaT}}$. Above the spike threshold, high threshold activated $\mathrm{I}_{\mathrm{CaP}}$ takes over and depolarizes the dendrite rapidly, finally leading to the generation of dendritic spikes. The amplitude of dendritic spikes doesn't increase further with the stimulation intensity and is mainly determined by the struggle among $\mathrm{I}_{\mathrm{CaP}}, \mathrm{I}_{\mathrm{KV} 3}$ and high conductance calcium activated $\mathrm{K}^{+}$currents $\left(\mathrm{I}_{\mathrm{BK}}\right)$. Injecting a negative current can eliminate the PF input evoked dendritic spikes by lowering the membrane potential which implies less activation of the $\mathrm{I}_{\mathrm{CaT}}$ and subsequent less amplification of the EPSP. We also find that the simulated dendritic spikes can't propagate to the whole dendrite due to the regulating role of mainly $\mathrm{I}_{\mathrm{BK}}$ and $\mathrm{I}_{\mathrm{KV} 3}$. Surprisingly by partially blocking $\mathrm{I}_{\mathrm{KV} 3}$ and $\mathrm{I}_{\mathrm{BK}}$ parallel fiber evoked dendritic spikes can propagate to the whole dendrite because of the broadening of its width.

The calcium influx by dendritic spikes is vital to a lot of calcium dependent processes like synaptic plasticity. Understanding the mechanism of generation of the local dendritic spikes evoked by PF stimulus and how their localized nature works will help us better explore how information is processed in the PC dendrite.

Published: 18 December 2015

\section{References}

1. Rancz EA, Hausser M: Dendritic calcium spikes are tunable triggers of cannabinoid release and short-term synaptic plasticity in cerebellar Purkinje neurons. J Neurosci 2006, 26(20):5428-5437.

2. Anwar $\mathrm{H}$, Hong $\mathrm{S}$, De Schutter $\mathrm{E}$ : Controlling $\mathrm{Ca}^{2+}$-activated $\mathrm{K}^{+}$channels with models of $\mathrm{Ca}^{2+}$ buffering in Purkinje cells. Cerebellum 2012, 11(3):681-693.

3. Otsu Y, Marcaggi P, Feltz A, Isope P, Kollo M, Nusser Z, et al: Activitydependent gating of calcium spikes by A-type $\mathrm{K}^{+}$channels controls climbing fiber signaling in Purkinje cell dendrites. Neuron 2014, 84(1):137-151.

doi:10.1186/1471-2202-16-S1-P53

Cite this article as: Zang and De Schutter: The ionic mechanism of the Purkinje cell dendritic spikes generation and propagation: a model exploration. BMC Neuroscience 2015 16(Suppl 1):P53. 